\title{
The Open Method of Coordination and the Governance of the Lisbon Strategy
}

\section{Jonathan Zeitlin}

University of Wisconsin-Madison EUSA conference, May 16-19, 2007 


\section{Plan of the talk}

- I. Revising the Lisbon Strategy: What was at stake?

- II. Where's the evidence?

The OMC in action

- III. What's left of Lisbon and the OMC?

- Closing the implementation gap through better governance?

- Reorienting the relaunch? Towards Lisbon III 


\section{Revising the Lisbon Strategy: What Was at Stake?}

- Ambiguities of the original Lisbon Agenda: something for everyone

- Competitiveness: liberalization and structural reform

- Innovation: a dynamic knowledge-based economy

- Sustainable economic growth

- Full employment: more and better jobs

- Greater social cohesion: fight against poverty/social exclusion, modernization of the European Social Model

- Environmental sustainability

- added in 2001 under the Swedish presidency 


\section{Lisbon's contested legacy}

- Rival interpretations of the Lisbon Strategy

- One focused on competitiveness and innovation

- 'Making the EU the most competitive and dynamic knowledge-based economy in the world by 2010'

- Another focused on new balance between social and economic dimensions of European integration

- 'socio-economic policy triangle': equal weight for full employment and social cohesion alongside growth/competitiveness/fiscal stability as EU objectives 


\section{Lisbon's contested legacy (2)}

- Ongoing struggle for control of EU policy coordination between economic and social actors

- ECFIN/Ecofin/EPC vs. EMPL/EPSCO/EMCO-SPC

- Ongoing critique by 'competitiveness lobby' of slow progress towards economic liberalization

- DGs Internal Market/Enterprise, business groups, think tanks, financial press

- Changing political composition of the Council

- Election of new center-right governments, 2001-4 


\section{OMC as a new governance instrument for Lisbon Strategy}

- Reconciling pursuit of European objectives with respect for national diversity \& subsidiarity through iterative benchmarking of progress against common indicators

- Promoting mutual emulation and cross-national learning by comparison of different approaches to shared problems

- A ‘third way' for EU governance between harmonization/centralization and regulatory competition/fragmentation

- Never intended as sole governance instrument for Lisbon

- to be combined with other EU policy tools (legislation, social dialogue, structural funds, community action programs, etc.) 


\section{Ambiguities of OMC}

- Recipe, cookbook, or architecture?

- Multiplication of procedural variations

- 'Lite' recipes/missing elements in many newer OMCs

- Convergence of what?

- Performance or policies?

- Open in what sense?

- Role of EU recommendations?

- Participation by non-state/subnational actors?

- A tool for building Social Europe or for avoiding new EU social legislation? 


\section{Critique and contestation}

- OMC as a potential threat to Community Method

- OMC as an infringement of subsidiarity

- Intrusion of EU into reserved competences of MS

- Convention stalemate over constitutionalization

- Struggle over review/reform of EES (2002-4)

- Simplified guidelines/quantitative targets

- Participation of non-state/subnational actors

- Commission or MS as agenda setter for national reform? (Kok Employment Task Force) 


\section{OMC and Lisbon Strategy review}

- OMC doubly called into question by 2004-5 Lisbon Strategy review

- Horizontally

- Balance and integration between distinct policy coordination processes/objectives

- Vertically:

- Effectiveness in securing Member State progress towards common European objectives 


\section{Kok Report (2004)}

- Criticized OMC for weakness of incentives for MS policy delivery

- But also noted ineffectiveness of Community Method in ensuring implementation of directives

- Called for refocusing of objectives and targets on growth and employment

- To be supported by intensified peer pressure on MS (naming, shaming, faming/league tables) 


\section{Barroso Commission (Lisbon New Start 2005)}

- Criticized OMC for failing to mobilize MS commitment to implementation of strategy

- Rejected naming \& shaming approach

- Called for new reform partnerships between Commission and MS, and between national governments and domestic stakeholders

- From sectoral, multilateral policy coordination (OMC) to integrated, bilateral dialogue on national reform programs 


\section{Beneath the debate: old and new cleavages}

- Supporters vs. opponents of social regulation

- Market liberals vs. social democrats

- Social welfare as a by-product of economic growth vs. social protection as a productive factor

- Supporters vs. opponents of Europeanization

- 'Federalists' vs. 'subsidiarists'

- Political will vs. experimental policy learning

- EU \& MS already know what to do in terms of economic and social reforms, but have lacked political will to implement them

- Alternative view: ongoing experimentation and policy learning are needed to discover how best to pursue multi-dimensional objectives in diverse national contexts 


\section{Where's the Evidence?}

- Kok Lisbon Strategy Report

- Unbalanced composition

- Dominated by economists and business figures

- Limited expertise on social/employment policies

- No systematic review of OMC processes

- Revised Lisbon Strategy/New Start

- Drafted primarily by DG Enterprise

- Appears to have ignored internal and external evidence on successes and failures of different OMC processes 


\section{Advancing the European knowledge economy through OMC: a failure?}

- Weak performance of innovation/information society initiatives within Lisbon Strategy

- Lack of progress towards 3\% R\&D target

- Limited impact/visibility of eEurope policies

- 'Lite' OMC recipes and fragmentary architectures

- European Action Plans, objectives, targets, indicators, benchmarking/scoreboards

- But no agreed National Action Plans, systematic monitoring/reporting, peer review, or country-specific recommendations; weak mutual learning mechanisms

- External evaluation (Tavistock Institute 2005):

OMC in these areas 'cannot yet be said to be a success or failure': 'simply has not been fully implemented' 


\section{The OMC in action: \\ employment and social inclusion}

- Employment and social inclusion: most fully developed and institutionalized OMC processes

- Methodological problems of assessing the causal impact of an iterative policymaking process based on collaboration between EU institutions and MS without legally binding sanctions

- But now a large body of empirical research, based on both official and independent sources

- Synthetic overview in Zeitlin \& Pochet (eds.), The OMC in Action (P.I.E.-Peter Lang, 2005) 


\section{OMC in employment and social inclusion: a qualified success}

- Improvements in EU employment performance

- Structural improvements, 1997-2001

- But connections to EES complex and uncertain

- Substantive policy change

- Increased political salience/ambition of national employment and social inclusion policies

- Broad shifts in national policy thinking

- Some influence on specific reforms/programs

- Two-way interaction between OMCs and national policies rather than one-way impact 


\section{OMC in employment/inclusion: a qualified success (2)}

- Procedural shifts in governance/policymaking

- Horizontal integration across policy areas

- Improved statistical and steering capacity

- Vertical coordination between levels of governance

- Participation of non-state/subnational actors

- Particularly strong mobilization in social inclusion

- Uneven but growing participation in EES

- Social NGOs and local/regional authorities more active than social partners 


\section{OMC in employment and inclusion: a qualified success (3)}

- Mutual learning

- Identification of common challenges and promising policy approaches

- Enhanced awareness of policies, practices, and problems in other MS

- Statistical harmonization and capacity building

- MS stimulated to rethink own approaches/practices, as a result of comparisons with other countries and ongoing obligations to re-evaluate national performance against European objectives 


\section{OMC in employment and inclusion: limitations}

- Lack of openness and transparency

- Dominant role of bureaucratic actors in OMC processes at both EU and national level

- Weak integration into national policy making

- NAPs as reports to EU rather than operational plans

- Low public awareness and media coverage

- Little bottom-up/horizontal policy learning

- Few examples of upwards knowledge transfer and cross-national diffusion from innovative local practice 


\section{A reflexive reform strategy}

- Overcome limitations of existing OMC processes by applying method to its own procedures

- Benchmarking, peer review, monitoring, evaluation, iterative redesign

- Ongoing reforms as evidence of practical viability

- Strengthening of peer review/mutual learning programs

- Proposals by EU institutions for greater openness, stakeholder participation, and 'mainstreaming' of OMCs into domestic policy making (2003-6) 


\section{What's Left of Lisbon and the OMC?}

- Rebalancing the Lisbon Strategy

- Retreat by Barroso Commission from attempt to exclude social cohesion from revised Lisbon Strategy

- Successful EU-level campaign by social NGOs, with support from key MS and European Parliament

- Social objectives reinstated in Lisbon Strategy by 2005 Spring European Council Presidency Conclusions

- Including commitment to decisive reduction of poverty \& social exclusion

- Reaffirmed in 2006/2007 Spring European Council Conclusions 


\section{Saving the social OMCs}

- Social protection OMCs reaffirmed

- Inclusion, pensions, health care

- Three 'strands' streamlined into an integrated process with both common and specific objectives

- Social OMCs to ‘feed into' new Lisbon Strategy

- Weak influence on NRPs, with some exceptions depending on national priorities

- Joint Report, key messages $\rightarrow$ Spring Euro Council

- Continuing struggle with Barroso Commission priorities

- Monitoring Lisbon Strategy impact on social cohesion ('feeding out') - little evidence of this so far 


\section{Integrating the economic and employment guidelines}

- Bigger change on employment side, through integration of EEGs with BEPGs

- Main thrust of existing EEGs preserved, including linkage to overarching objectives

- But only at cost of maintaining complexity

- Continuing tensions between economic and employment actors within new integrated guidelines/coordination process 


\section{Closing the implementation gap through better governance?}

- Simplification of objectives \& reporting?

- Increased national ownership \& participation?

- From multilateral coordination to bilateral consultation?

- Results of first two rounds of NRPs not encouraging 


\section{Simplification or specificity?}

- Difficulty of sustaining simplified focus

- Need for specificity and detail to coordinate complex policy areas effectively

- Interdependence between growth/jobs and other policy areas w/ separate coordination processes

- social protection/inclusion, education/training, environment/sustainable development

- Multiplication of new priorities, coordination processes \& reporting obligations

- E.g. better regulation, immigrant integration 


\section{Reduced monitoring and coordinating capacity}

- MS free to set own priorities in NRPs

- National employment reporting less extensive and more uneven than in NAPs

- Diminished reference to guidelines, targets, and common indicators

- Commission assessment methodologies disputed between EPC and EMCO

- Selective peer review of NRPs

- Focused on 3 key themes in employment

- Broader in macro/micro economic policies 


\section{Decoupling mutual learning from policy making?}

- Mutual learning activities stepped up within EU committees (EMCO, SPC)

- Peer review/exchange of good practices, thematic seminars, national follow-up activities

- Risk of decoupling mutual learning from national policy making: opposite of mainstreaming

- Perverse effects of recent French and German employment reforms as cautionary examples

- Risk to institutional capacity building and governance improvements at EU and MS levels 


\section{Increased national ownership and participation (1)?}

- Round 1 (2005)

- Limited ambition/novelty of many NRPs

- Repackaging of national policies very common

- Low status of Lisbon coordinators in many MS

- Low public and media visibility

- Little involvement of national parliaments

- Limited/variable involvement of social partners

- Little involvement of subnational \& civil society actors

- A clear step backwards from NAPs/empl \& incl in inclusion of civil society 


\section{Increased national ownership and participation? (2)}

- Big Commission push for greater national ownership in $2^{\text {nd }}$ round of NRP implementation (2006)

- Creation of new consultative/coordination bodies

- Upgrading of political status of Lisbon coordinators

- Wider involvement of national parliaments, social partners, regional/local authorities

- Little opportunity for participation by social NGOs \& other civil society groups

- But still low strategic commitment from non-state actors \& limited public appeal of relaunched Lisbon Strategy

- Especially where social cohesion objectives are excluded from NRPs, and process is dominated by finance/economics ministries 


\section{The return of recommendations: friendly advice or naming \& shaming?}

- Commission did not make formal recommendations to MS on 2005 NRPs

- Just flagged 'points requiring further attention'

- 2006 Annual Progress Report includes country-specific recommendations

- MS progress in implementing revised Lisbon Strategy graded from "limited" to "very good"

- MS receive 0-5 recommendations, + 3-5 additional 'focus points'

- Lack of transparency/legitimacy in evaluation criteria

- Recommendations negotiated bilaterally with MS

- EMCO rejects peer review/multilateral surveillance of countryspecific employment recommendations 


\section{Bilateral consultation or multilateral coordination?}

- Difficulty of sustaining shift from multilateral coordination to bilateral consultation between Commission and MS

- Low quality/lack of comparability of many NRPs

- Continuing commitment of MS to comparing policy approaches/performance \& mutual learning

- Commission plans for renewed mutual surveillance on 'horizontal' issues

- e.g. energy, research/innovation, flexicurity

- Mutual learning workshops within network of National Lisbon Coordinators on priority areas

- e.g. one-stop shops for setting up new enterprises, business-university cooperation, extending working lives of older workers 


\section{Deficiencies of Lisbon II}

- Inadequate integration of social, economic, and employment policies

- Decoupling of policy making from mutual learning

- Reduced monitoring and coordinating capacity

- Insufficient openness to civil society actors

- National commitment remains limited 


\section{Reorienting the relaunch? Towards Lisbon III}

- Mounting pressure to reorient the Lisbon Strategy

- 'Un Nouvel Élan pour l'Europe Sociale' declaration of 9 MS Labor/Social ministers

- Social priorities of EU Team Presidency (DE/PT/SI)

- 2007 Spring European Council conclusions

- SPC debate on strengthening the social dimension of the Lisbon Strategy

- 10-year review of the EES (2007)

- 2008 revision of Integrated Guidelines 